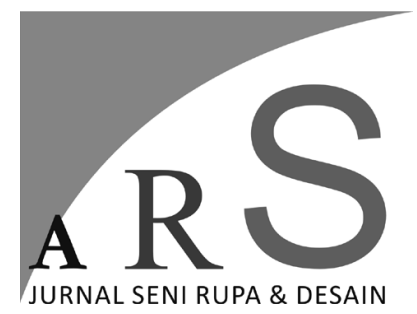

Volume 23 Nomor 3 September - Desember 2020

\section{REDESIGN PAKAIAN SECONDHAND BERWARNA PUTIH DENGAN TEKNIK BATIK TULIS MENGGUNAKAN PENCELUPAN PEWARNA ALAMI}

\author{
Shabrina Defti Widyaputri \\ Program Studi Kriya, Fakultas Industri Kreatif \\ Universitas Telkom, Bandung, Telp. 082282432519, \\ E-mail: shabrinadw.sheby@gmail.com
}

\begin{abstract}
ABSTRAK
Pasar Cimol Gedebage adalah tempat terbesar di kota Bandung yang menjual pakaian secondhand. Pasar Cimol Gedebage menjual berbagai model dan warna pada pakaian secondhand, biasanya berbahan katun, linen, dan sifon. Dilihat dari segi warna salah satunya pakaian secondhand berwarna putih yang sudah cacat seperti menguning atau terkena noda warna lain sulit dijual ataupun dijual dengan harga yang lebih murah. Oleh karena itu, peneliti melihat potensi diolah menjadi produk fashion baru layak pakai dan menjadikan konsep dengan style yang menarik, menggunakan teknik redesign dan teknik surface textile design yaitu batik tulis dengan pencelupan pewarna alami. Motif pada batik tulis yang diangkat salah satu batik dari Yogyakarta yaitu batik parang barong dan parang curigo. Penelitian ini menggunakan metode kualitatif dan pengumpulan data melalui studi literatur sebagai landasan dalam penelitian, observasi lapangan guna melihat ketersediaan bahan yang akan digunakan, wawancara secara acak kepada pedagang di Pasar Cimol Gedebage, dan eksplorasi guna mengetahui teknik yang optimal untuk diaplikasikan pada bahan baku yang akan diolah. Penelitian dilakukan untuk memberikan manfaat jangka umur produk dan agar tidak menambah dampak buruk bagi lingkungan dengan menggunakan teknik redesign pada pakaian secondhand berwarna putih, Selain itu juga untuk meningkatkan nilai fungsi, estetika, dan nilai ekonomi pada pakaian secondhand tersebut.
\end{abstract}

Kata kunci : pakaian secondhand, batik tulis, redesign.

\begin{abstract}
Redesign White Secondhand Clothes With Batik Writing Techniques Using Natural Color Dying. Cimol Gedebage Market is the biggest place in the city of Bandung that sells secondhand clothing. Cimol Gedebage Market sells a variety of models and colors in secondhand clothing, usually made from cotton, linen, and chiffon. In terms of color, one of which is white secondhand clothing that has been deformed, such as yellowing or being stained by other colors, is difficult to sell or sell at lower prices. Therefore, researchers see the potential to be processed into new fashion products suitable for use and to make concepts with attractive styles, using redesign techniques and surface textile design techniques, namely batik with natural dye dyeing. The motifs on the written batik raised by one of the batik from Yogyakarta are the parang barong batik and the curigo parang. This study uses qualitative methods and data collection through literature studies as a basis for research, field observations to see the availability of materials to be used, random interviews with traders in the Cimol Gedebage Market, and exploration to find out the optimal techniques to be applied to the raw materials to be used. processed. The research was conducted to provide product long-term benefits and so as not to add to the adverse impact on the environment by using redesign techniques on white secondhand clothing, in addition to increasing the functional value, aesthetics, and economic value of the secondhand clothing
\end{abstract}

Keywords : secondhand clothing, batik, redesign. 


\section{Pendahuluan}

Pasar Cimol Gedebage adalah tempat terbesar dikota Bandungyang menjual pakaian secondhand, pakaian secondhand impor dari luar negeri seperti Korea, Jepang, Cina, Prancis, Amerika, dan Inggris. Pasar Cimol Gedebage berjumlah 1080 toko, yang dimulai pada tahun 2009 yang menjual berbagai macam pakaian secondhand seperti dress, kemeja, outer, blouse, celana, rok, dan pakaian lainnya tentu dengan kualitas yang masih layak pakai. Dari observasi yang dilakukan, pakaian secondhand juga masih banyak diminati oleh setiap masyarakat menurut Lestari(2017) menyebutkan bahwa bisnis fashion semakin berkembang di Bandung, namun pakaian bekas imporpun nyatanya masih diminati. Walaupun tetap ada saja yang kontra terhadap pakaian bekas impor ini karena didasari kualitas kebersihan dan kesehatannya.

Dari beberapa toko yang ada di Pasar Cimol Gedebage menjual berbagai model dan warna, biasanya kebanyakan dijual berbahan katun, linen, dan sifon. Adapun dilihat dari segi warna salah satunya pakaian Secondhand berwarna putih yang sudah cacat seperti menguning atau terkena noda warna lain sulit terjual karena itu pembeli lebih memilih warna lain daripada pakaian berwarna putih. Biasanya juga penjual menjual pakaian secondhand yang cacat dijual dengan harga yang lebih murah, karena itu penulis menjual pakaian secondhand yang caca dijual dengan harga yang lebih murah, karena itu penulis akan memanfaatkan pakaian yang berwarna putih untuk dijadikan pakaian layak pakai.

Berdasarkan permasalahan diatas, pakaian secondhand berwarna putih bisa dimanfaatkan untuk dijadikan pakaian layak pakai dengan teknik surface textile design dan melakukan redesign terhadap pakaian secondhand berwarna putih. Kegiatan tersebut dalam rangka salah satu solusi untuk mengurangi volume limbah tekstil yang memiliki kecacatan pemakaian sebelumnya dengan menggunakan metode upcycle pada pakaian secondhand tersebut, menurut Febri dalam muthu (2019) upcycle yaitu menambahkan nilai ke produk lama atau bekas menjadi barang yang bernilai lebih tinggi. Untuk memberikan solusi dari permasalahan tersebut, diharapkan dapat meningkatkan nilai ekonomis dan estetiknya pada pakaian secondhand tersebut.

Pakaian secondhand berwarna putih memiliki potensi dapat diolah menjadi produk fashion baru layak pakai dan menjadikan konsep dengan style yang lebih menarik, menggunakan teknik surface textile design yaitu batik tulis dengan pencelupan pewarna alami dikarenakan agar tetap menjaga kelestarian budaya tradisonal Indonesia yang mempunyai nilai estetika yang tinggi dan tetap ramah lingkungan. Penelitian ini terinspirasi untuk melestarikan teknik tradisional Indonesia yaitu batik menggunakan canting seperti yang dikatakan oleh Rahma dalam Yudoseputri (2017), mengatakan bahwa batik merupakan tradisi yang memiliki latar belakang yang kuat dengan bangsa dan rakyat Indonesia dalam segala bidang dan bentuk kebudayaan maupun kehidupan seharihari. Tingkat kesulitan dalam proses pembuatan batik dianggap sebagai karya yang memiliki nilai dan perpaduan seni yang tinggi. Selain itu, penulis mengangkat salah satu batik tertua dari Yogyakarta yaitu batik parang barong dan parang curigo yang memiliki filosofi tersendiri yaitu batik parang barong motif yang hanya boleh digunakan untuk raja, terutama dikenakan pada saat ritual keagamaan dan meditasi karena mempunyai makna agar raja selalu hati-hati dan dapat mengendalikan diri dan batik parang curigo memiliki filosofi digunakan untuk menghadiri pesta yang memakainya memiliki kecerdasan, kewibawaan, serta ketenangan. Namun, saat ini batik parang sudah banyak memiliki karakteristik estetika batik itu sendiri sehingga jika di redesign pun tidak menghilangkan ciri khas dari motif tersebut saat digunakan secara massal.

Dari uraian diatas, maka rumusan masalahnya adalah:

a. Bagaimana cara memanfaatkan dan mengolah pakaian secondhand berwarna putih yang terdapat di Pasar Cimol Gedebage?

b. Bagaimana cara mengolah pakaian secondhand berwarna putih dengan menggunakan teknik batik tulis dan pewarna alami ?

c. Bagaimana cara menerapkan pakaian secondhand berwarna putih menjadi pakaian layak pakai produk fashion dengan style yang menarik? 


\section{Metode Penelitian}

Proses dalam mewujudkan karya ini melalui tiga tahapan penciptaan karya yaitu eksplorasi, perancangan dan perwujudan.

\section{Tahap eskplorasi}

Eksplorasi merupakan tahap awal dalam proses penciptaan karya, yang meliputi pencarian sumber dari data lapangan, wawancara pada narasumber, dan pengumpulan data, kemudian dilanjutkan dengan pengolahan dan analisis data untuk mendapatkan data penting sebagai konsep pemecahan masalah yang hasilnya dipakai sebagai dasar perancangan.

Pada tahapan proses produksi menggunakan metode upcyle Menurut Febri dalam Muthu (2019) Istilah "Upcycling" pertama kali diciptakan oleh Reiner Pilz diterbitkan pada tahun 1994 yang menjelaskan konsep menambahkan nilai ke produk lama atau bekas menjadi barang yang bernilai lebih tinggi. Adapun proses yang dilakukan yaitu sebagai berikut : memahami tujuan, menganalisis konsep, mengeksplorasi konsep, menyusun solusi, dan merealisasikan produk.

\section{a. Teknik Batik Tulis}

Teknik batik tulis merupakan jenis batik yang dihasilkan dari malam atau lilin pada kain menggunakan canting dengan cara ditulis sesuai motif yang diinginkan, kemudian dilanjutan dengan pewarnaan, setelah proses pewarnaan selesai tahap akhir adalah proses fiksasi menurut Mayliana (2016) mengatahan bahwa proses fiksasi yaitu tahap yang dilakukan pada akhir proses pewarnaan yang berfungsi untuk mengunci warna supaya warna tidak mudah lepas, proses fiksasi menggunakan tawas dan dilakukan dalam waktu 10 menit. Pembuatan kain batik memakan waktu yang lama, karena kain batik dibuat dengan menggunakan lilin dan canting untuk batik tulis. Menurut Kusumawardhani (2012) menyebutkan bahwa proses dalam pembuatan batik tulis inilah yang membuat batik tulis ini menjadi khas dan bernilai tinggi, sehingga harganya menjadi lebih mahal.

\section{b. Fashion}

Secara khusus dapat dilhat dari sisi etimologi maka kata fashion ini berhubungan erat dengan sebuah kata dari Bahasa latin, yaitu factio yang memiliki arti "membuat". Oleh karena itu, maka fashion merupakan sebuah aktivitas yang sedang dilakukan oleh seseorang menurut Nargis dalam Kementrian Perdagangan Republik Indonesia (2008), mengatakan bahwa perkembangan fashion diseluruh dunia turut serta meningkatkan selera fashion masyarakat di Indonesia, di bidang ekonomi dan industri kreatif. Pakaian dari zaman dahulu saat pertama kali dikenakan untuk menutupi tubuhnya sesuai dengan iklim dan gaya hidup pada perbedaan daerah. Pakaian biasanya digunakan saat acara resmi, busana seragam, pakaian sehari-hari (ready to wear), dan pakaian pesta.

\section{c. Batik parang barong dan parang curigo}

Motif batik parang merupakan salah satu motif paling tua di Indonesia yang berasal dari Yogyakarta menurut Sedjati (2019) mengatakan bahwa menciptakan dan mengembangkan motif batik baru yang memiliki gaya atau corak Yogyakarta merupakan bentuk kepedulian dalam rangka mendukung dan mempertahankan status Indonesia sebagai warisan budaya sebagai kota batik dunia pada bulan oktober 2014 oleh World Craft Center(WCC). Arti dari batik parang yaitu kata parang berasal dari pereng atau lereng atau tebing yang memiliki bentuk garis diagonal sebagaimana yang ada dalam motif batik parang. Motif batik parang merupakan batik asli Indonesia yang sudah ada sejak zaman keraton, pada 
zaman dahulu motif batik parang ini menjadi pedoman utama dalam menentukan derajat kebangsawaan seseorang. Bahkan pada zaman dahulu motif parang hanya boleh dikenakan oleh raja dan keturunannya, hingga saat ini motif parang telah mengalami banyak perkembangan tanpa menghilangkan kesan estetika pada batik itu sendiri.

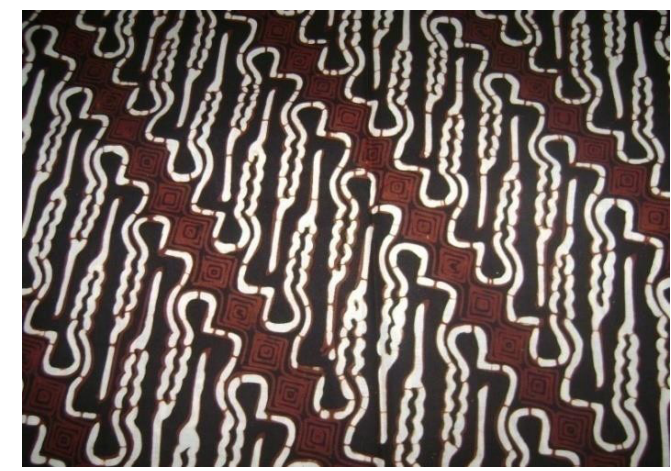

Gambar 1. Motif batik parang barong (Sumber : tumpi.id, 2016)

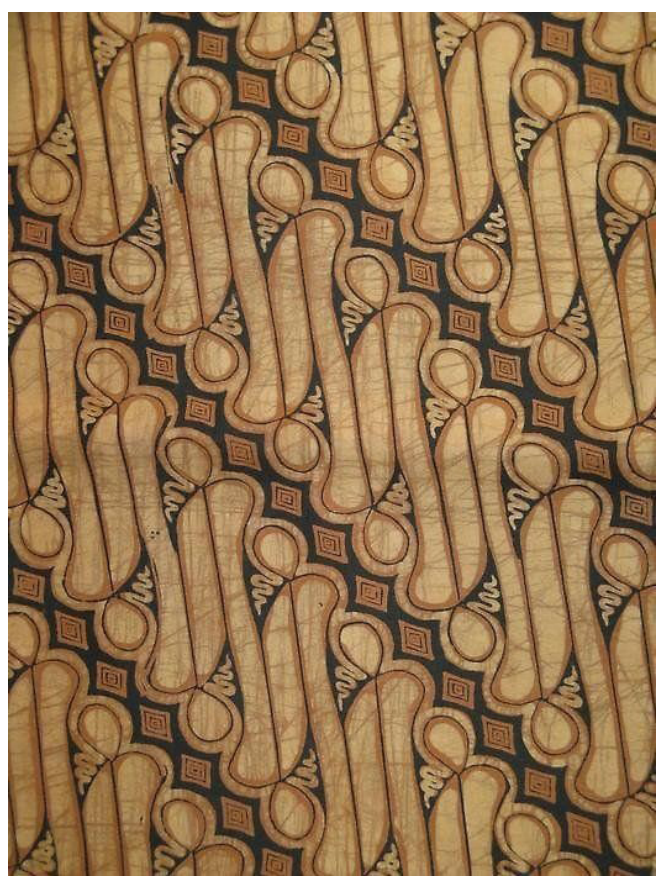

Gambar 2. Motif batik parang curigo (Sumber : tumpi.id, 2016)

\section{d. Pewarna Alam}

Sejak zaman dahulu, bangsa Indonesia telah mengenal dan bahkan menggunakan pewarna tekstil yang berasal dari alam. Kain tradisional Indonesia sudah lama terkenal dengan keindahan motifnya dan komposisi warnanya yang mengikat, Perkembangan sekarang mengembangkan potensi pewarna alami yang aman serta ramah lingkungan. Jenis-jenis pewarna alami selain pewarna alami saat proses pencelupan pada kain biasaya direbus, penelitian ini menggunakan pewarna dingin berbentuk cair yaitu tingi yang terbuat dari kulit kayu tingi menghasilkan warna cokelat dan merah bata lalu pewarna alami merbau terbuat dari serbuk kayu merbau yang menghasilkan warna cokelat muda hingga cokelat tua.

\section{Tahap Perancangan}

Tahap perancangan diawali dari memberikan ide yang diperoleh dari hasil data lapangan ke dalam bentuk sketsa. Sketsa tersebut dijadikan desain alternative dan desain terpilih dengan tema sketsa etnic et mollis mengangkat gaya bohemian style. Sketsa- sketsa tersebut sebagai berikut:

\section{a. Sketsa alternatif}

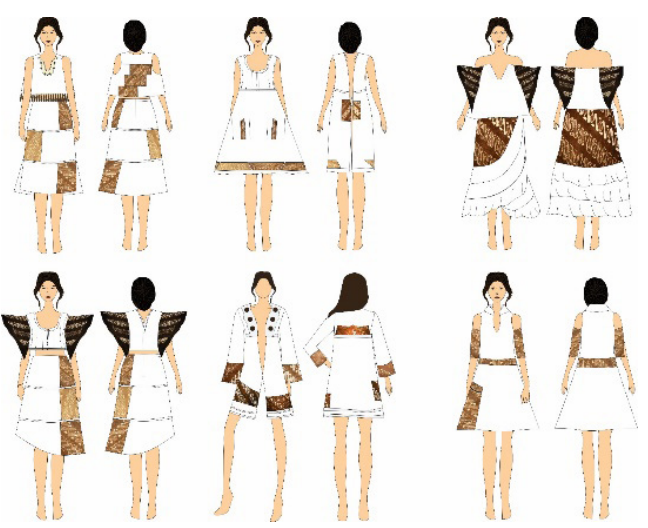

Gambar 3 sketsa alternatif (Sumber : Dokumen Shabrina, 2020) 
b. Sketsa Terpilih


Gambar 4 sketsa terpilih

(Sumber : Dokumen Shabrina, 2020)

\section{Tahap Perwujudan}

Untuk menghasilkan karya yang baik diperlukan beberapa tahapan dan proses pembuatan karya. Proses pembuatan tersebut meliputi pembuatan desain, menerapkan eksplorasi pada bahan karya, dan finishing (jahit karya yang akan diwujudkan)

\section{Pembahasan}

Hasil penelitian menunjukan bahwa dari data yang sudah dikumpulkan, mengangkat fenomena redesign pakaian secondhand berwarna putih, selanjutnya pakaian dari penelitian tersebut yang membawa dan membuat lahirnya sumber ide penciptaan sebuah karya.

Dalam pembahasan ini akan dibahas tentang karya yang dibuat sendiri yaitu redesign pakaian secondhand berwarna putih dengan teknik batik tulis menggunakan pencelupan pewarna alami.

\section{Tinjauan Karya \\ Deskripsi karya :}

Karya redesign pakaian secondhand berwarna putih dengan teknik batik tulis menggunakan pencelupan pewarna alami ini dimulai proses pengerjaanya pada tahun 2019, dengan menganalisis bagian reject dan defect pada pakaian secondhand berwarna putih yang di beli di Pasar Cimol Gedebage yaitu jenis dress, blouse, dan rok. Penerapan motif batik tulis menggunakan pencelupan pewarna alami pada bagian pakaian secondhand berwarna putih yang terkena noda dan reject. Bentuk motif yaitu batik parang barong dan parang curigo yang dibuat dengan teknik batik tulis dengan diaplikasikan pada pakaian menggunakan teknik patchwork. Posisi penempatan motif pada pakaian diterapkan dikarenakan untuk menutupi reject dan defect pada pakaian secondhand berwarna putih tersebut, Pemilihan warna untuk bentuk motif parang barong dan parang curigo diambil dari karakteristik motif batik itu sendiri.

\section{Tahap Perwujudan}

Proses perwujudkan merupakan proses yang dilalui oleh pengkarya dalam pengerjaan redesign pakaian secondhand berwarna putih sebagai berikut:

a. Pembelian pakaian secondhand berwarna putih di Pasar Cimol Gedebage. 




Gambar 5 Proses analisis pakaian secondhand berwarna putih

(Sumber : Dokumen Shabrina, 2019)

b. Pencucian pakaian secondhand berwarna putih

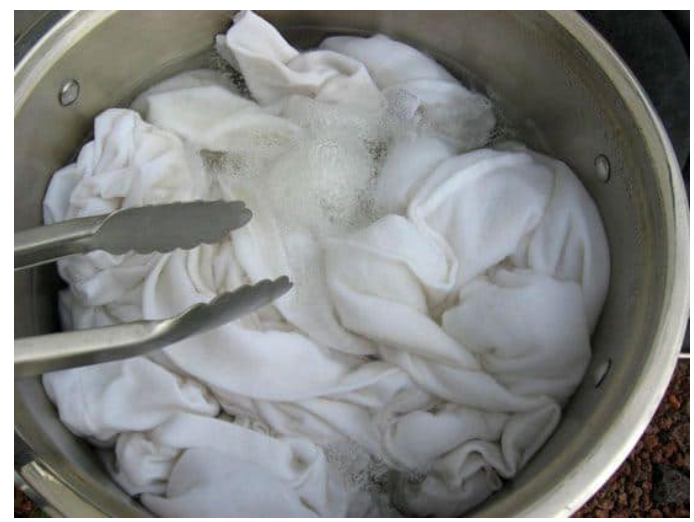

Gambar 6 Proses perebusan pakaian secondhand berwarna putih

(Sumber : Dokumen Shabrina, 2019)

c. Proses pembuatan desain digital menggunakan software coreldraw

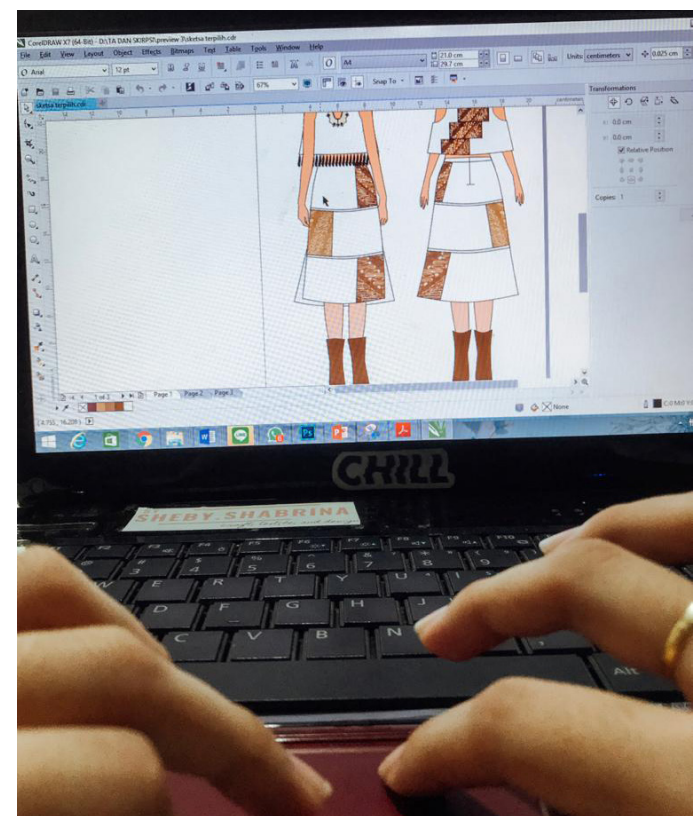

Gambar 7 Proses pembuatan desain (Sumber : Dokumen Shabrina, 2020) d. Proses penerapan eksplorasi yang akan digunakan sebagai aplikasi pelengkap pakaian 1. Pakaian secondhand berwarna putih jenis dress di redesign menjadi jenis cropptop, proses redesign pada pakaian karena ingin menambahkan nilai ekonomis, nilai estetika, dan nilai fungsi pada pakaian secondhand dikarenakan memiliki reject dan defect pada pakaian secondhand tersebut
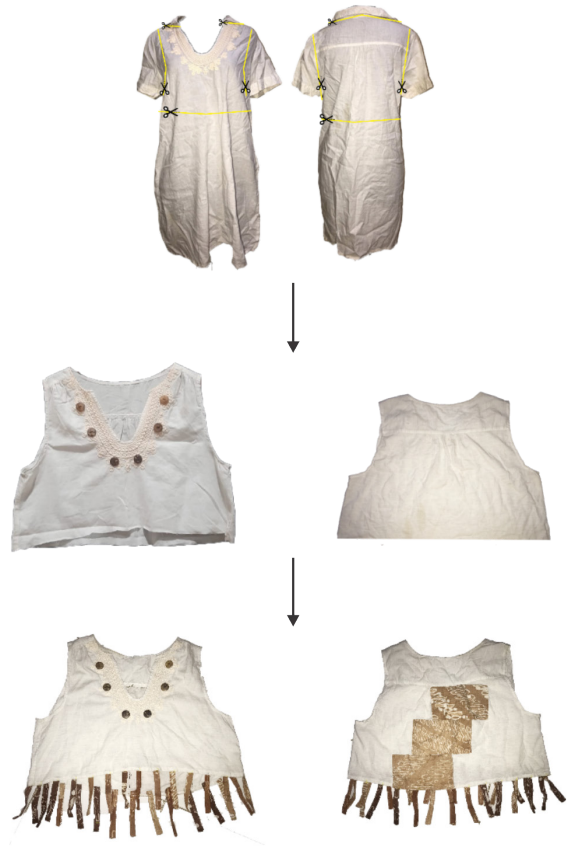

Gambar 8 Proses penerapan eksplorasi pada pakaian secondhand berwarna putih Sumber : Dokumen Shabrina, 2020)

2. Pakaian secondhand berwarna putih jenis rok, proses redesign pada pakaian secondhand berwarna putih dikarenakan memiliki reject dan defect pada pakaian tersebut.
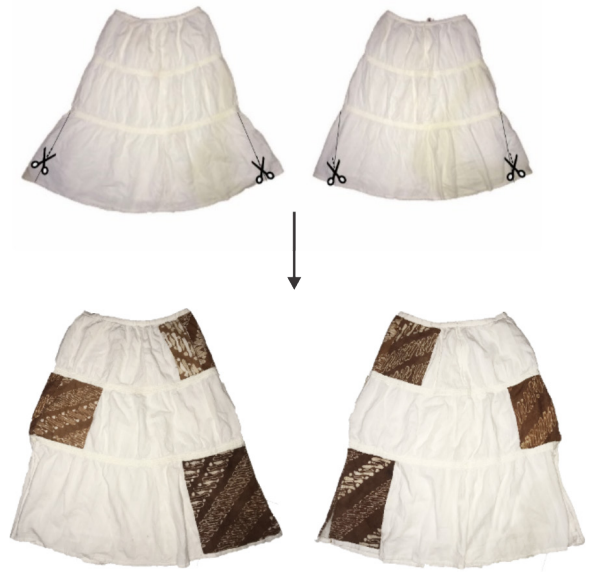

Gambar 9 Proses penerapan eksplorasi pada pakaian secondhand berwarna putih (Sumber : Dokumen Shabrina,2 020) 
3. Pakaian secondhand berwarna putih jenis blouse di redesign menjadi jenis outer, proses redesign pakaian secondhand dikarenakan memiliki reject dan defect pada pakaian secondhand tersebut

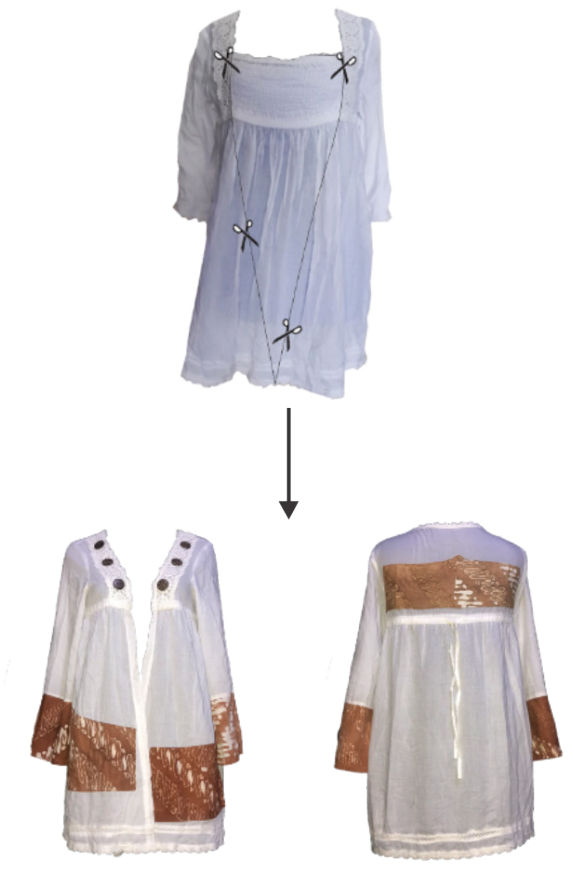

Gambar 10 Proses penerapan eksplorasi pada pakaian secondhand berwarna putih (Sumber : Dokumen Shabrina, 2020)

4. Teknik, Bahan, dan Alat Teknik, bahan, dan alat yang digunakan dalam proses pembuatan redesign pakaian secondhand berwarna putih ini adalah sebagai berikut:

a) Teknik

Pada karya ini menggunakan teknik batik tulis untuk eksplorasi yang akan diaplikasikan pada pakaian, lalu teknik patchwork untuk pengaplikasian dari potongan eksplorasi ke pakaian secondhand berwarna putih, dan teknik redesign yaitu pengulangan atau melakukan kembali untuk mengacu pada perubahan pakaian untuk karya yang akan diwujudkan.

b) Bahan

Pada karya ini bahan utama yang digunakan yaitu pakaian secondhand berwarna putih jenis dress, rok, dan blouse. c) Alat

Alat yang digunakan pada proses pembuatan karya ini adalah jarum dan benang untuk proses penjahitan bahan yang akan diredesign, lalu alat eksplorasi yaitu malam/lilin,canting,kompor listrik untuk batik, pemidangan, gunting, alat tulis, karbon kain dan ember.

\section{Kesimpulan}

Berikut adalah kesimpulan yang dapat diambil dari penelitian pakaian secondhand berwarna putih ini yaitu sebagai berikut:

a. Pakaian secondhand di Pasar Cimol Gedebage sangat melimpah dan sulit terjual, pada umumnya pakaian secondhand memiliki kecacatan Menganalisis bagian pakaian secondhandberwarnaputihmemilikikecacatan seperti tercampur noda warna lain,kotor, dan sobek, untuk menutupi hal tersebut dapat dengan eksperimen menggunakan teknik batik tulis dan pencelupan pewarna alami di beberapa bagian pakaian secondhand yang cacat dijadikan bahan untuk membuat eksplorasi teknik yang digunakan. Memakai bahan eksplorasi dari pakaian secondhand berwarna putih guna agar tidak menambah limbah pakaian.

b. Pakaian secondhand berwarna putih diolah dengan cara menambahkan motif batik parang barong dan curgio sebagai inspirasi menutupi kekurangan pada produk tersebut dengan menggunakan teknik batik tulis dan pencelupan pewarna alami tingi dan merbau menggunakan mordan akhir tawas dan tunjung karena agar tetap memiliki nilai ekonomis,estetika dan tidak menambah dampak buruk bagi lingkungan pada proses produk pakaian secondhand tersebut.

c. Pakaian secondhand berwarna putih agar menjadikan pakaian layak pakai menambahkan proses ke produk menggunakan teknik redesign dan patchwork. Dalam penelitian ini penulis mendapati salah satu pakaian secondhand berwarna putih menjadikan produk fashion dengan style yang menarik yaitu dress yang terdapat kotor bekas jamur dan kusam, bagian yang kotor dipotong 
dan dijadikan bahan untuk eksplorasi yang akan di batik, lalu yang semulanya dress berubah fungsi menjadi pakaian jenis cropped top , pada bagian depan terdapat hiasan crochet berwarna broken white lalu penulis menambahkan material kancing tempurung agar menambah kesan bohemian dan mempunyai nuansa warna yang sama dengan eksplorasi batik yang telah dibuat. Upaya yang dilakukan yaitu me-redesign pakaian secondhand menjadi produk fashion baru berupa outer, cropped top, dan rok yang lebih inovatif. Kegiatan redesign dalam penelitian ini memiliki konsep yang menyesuaikan target market yang dituju yaitu wanita berusia 1935 tahun beserta memasukan unsur budaya Indonesia yaitu batik parang barong dan parang curigo diambil dari motifdan pemilihan warna yang sesuai pada eksplorasi yang dibuat serta diaplikasikan pada pakaian secondhand berwarna putih, Selain itu, bohemian style menjadi acuan dalam me-redesign pakaian secondhand. Bohemian merupakan style yang berkarakter memiliki gaya yang cenderung artistik dan unik menjadi lebih bebas terlihat unsur etnik saat dipakai, sehingga produk fashion yang baru ini akan menjadi nilai estetik dan ekonomisnya, dikarenakan menerapkan teknik redesign dan metode upcycle dalam penelitian ini.

\section{Daftar Pustaka}

Lestari, L. (2017). Analisis preferensi konsumen terhadap pakaian bekas impor (Studi kasus pada pasar Gedebage Bandung). Universitas Telkom.

Febri, E . (2019). Optimalisasi Redesign Pakaian Secondhand Berbahan Polyester. Universitas Telkom.

Rahma, P. (2017). Pengolahan limbah kain batik sebagai aplikasi dekoratif produk fashion pakaian ready to wear. Universitas Telkom.

Kusumawardhani, R. (2012). How to wear Batik. Jakarta: Gramedia Pustaka Utama.

Behesti, N. (2019). Pengolahan Pakaian Secondhand Berbahan Denim Untuk Produk Fashion Menggunakan Teknik Surface Textile Design Yang Terinspirasi dari Jumputan Palembang. Universitas Telkom.
Sedjati, D. (2019). Keben (Barringtonia asiatica) Motif dan Pewarna Batik. Journal of Urban Society's Arts, Vol 8, No 2, 2-10

Mayliana, E. (2016). Pengaruh lama waktu mordanting terhadap ketuaan warna dan kekuatan Tarik kain mori dalam proses pewarnaan dengan zat pewarna sabut kelapa. Journal of Urban Society's Arts, Vol 5, No 1, 2-7 